\title{
Effect of height and weight on the in vivo recovery of transfused factor VIII C
}

\author{
A ARONSTAM, DS McLELlan, M WASSEF, PS MBATHA \\ From Treloar Haemophilia Laboratory, Lord Mayor Treloar Hospital, Alton, Hampshire
}

SUMMARY The in vivo recovery of factor VIII has been estimated on 84 occasions in 53 severely affected adolescent haemophiliacs. There was wide individual variation in recovery, which was not affected by differences in the administered dose. Recovery increased steadily with increasing surface area, and it was only over a surface area of $1.7 \mathrm{~m}^{2}$ that a recovery of $2 \%$ of factor VIII per unit per $\mathrm{kg}$ became the norm. It is suggested that the only safe assumption to make below that surface area is an in vivo recovery of $1.5 \%$.

The treatment of haemophilic haemarthroses with inadequate doses of factor VIII will predispose the joints to chronic synovitis, progressive arthropathy, and ultimately to crippling deformity. ${ }^{1}$ There are, however, potentially harmful side effects associated with adequate and excessive exposure to factor VIIIcontaining materials, ${ }^{2}$ which also strain human and financial resources. ${ }^{3}$ Clearly, the use of the correct dose of factor VIII in varying situations is of great importance.

Recent studies have identified minimum dosage schedules for bleeds of varying severity in specific sites, ${ }^{4}$ and in joints with or without previous and/or present damage. 5

If the minimum effective dose is to be used efficiently, it is crucial to be able to predict the rise in factor VIII activity that is likely to follow a given dose. A rise of $2 \%$ of average normal activity per unit of factor VIII concentrate is assumed by many authors, ${ }^{6-8}$ but there is evidence that the response in children is lower than in adults. ${ }^{9} 10$ Biggs and Rizza ${ }^{6}$ have recommended that a rise of $1.5 \%$ of average normal factor VIII be assumed for every transfused unit per kilogram in children. No guidance is given about when to change the dosage schedule from paediatric to adult expectations.

We have presumed that any variation is likely to be related to relative plasma volumes and that the transition will probably occur during adolescence. We have, therefore, estimated the post-transfusion rise of factor VIII on 84 occasions in 53 adolescent haemophiliacs and have studied the relation to weight, height and administered dose.

Accepted for publication 8 July 1981

\section{Patients and methods}

The subjects studied were 53 severely affected adolescent haemophiliacs (factor VIIIC $<1 \%$ ) resident at the Lord Mayor Treloar College.

Blood samples were taken immediately before and between 20 and 30 minutes after infusions of factor VIII-containing material. Samples were immediately dispensed into plastic tubes containing $3.8 \%$ sodium citrate ( 9 vols blood to $1 \mathrm{vol}$ anticoagulant). The plasma was separated within two hours by centrifuging at $2000 \mathrm{~g}$ at $4^{\circ} \mathrm{C}$ and tested immediately.

Factor VIIIC was tested by a two stage method modified from that of Denson. 11 During the year in which the study took place, approximately 700 factor VIII assays were undertaken in our laboratory, $10 \%$ of which were done in duplicate. Average variation between operators was never more than $10 \%$.

All weights and heights used were obtained within two months of the relevant estimation. Height was measured with patients standing without shoes and with their heels back in contact with an upright scale. Body surface area was calculated using a nomogram based on the formula of $\mathrm{Du}$ Bois and Du Bois. ${ }^{12}$

Recovery or response was expressed as the percentage rise of factor VIII per unit of factor VIII/ $\mathrm{kg}$ infused. The dose of factor VIII infused was based on the unit-values given by the manufacturer. These were specifically checked on 19 occasions during the study. The preparations used were fractionated by Travenol laboratories, Armour, Immuno and the Lister Institute. On 16 occasions the assayed potency deviated by less than $10 \%$ from 
the manufacturer's stated potency and on no occasion was a deviation of more than $20 \%$ noted.

Haemoglobin concentrations were estimated using a Coulter model " $S$ " counter. The relation between haemoglobin concentrations and recovery was calculated using Kendall's test of rank correlation.

\section{Results}

\section{EFFECT OF INCREASING WEIGHT}

A scattergram shows the dose response in small groups of boys with similar weights (Fig. 1). An increasing response is noted from the group weighing less than $40 \mathrm{~kg}(\overline{\mathrm{x}}=1.67 \pm 0.19)$ through the $40-44 \mathrm{~kg}$ group $(\overline{\mathrm{x}}=1.79 \pm 0.24)$ to the $45-49 \mathrm{~kg}$ group $(\bar{x}=2 \cdot 16 \pm 0.43)$. A similar response is seen from $55-59 \mathrm{~kg}(\overline{\mathrm{x}}=1.87 \pm 0.29)$ through $60-64 \mathrm{~kg}$ $(\bar{x}=2.07 \pm 0.27)$ to the $65-69 \mathrm{~kg}$ group $(\bar{x}=2.17 \pm$ $0.35)$. There are significant differences between the under $40 \mathrm{~kg}$ and the $45-49 \mathrm{~kg}$ groups $(\mathrm{p}<0.02)$ and between the $40-44 \mathrm{~kg}$ and the $45-49 \mathrm{~kg}$ groups $(\mathrm{p}<0.005)$. The difference between the $55-59 \mathrm{~kg}$ group and the 65-69 group is also significant (p < 0.05).

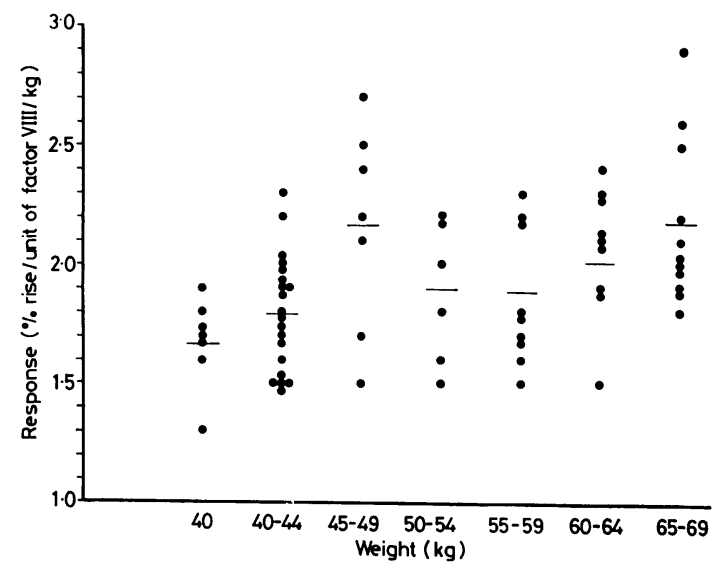

Fig. 1 Effect of increasing weight on the dose response.

EFFECT OF INCREASING SURFACE AREA The dose response of small groups of boys with similar surface areas are shown in Fig. 2. The response begins to increase in the group with a surface area of 1.6 to $1.69 \mathrm{~m}^{2}(\overline{\mathrm{x}}=1.90 \pm 0.38)$ through the 1.7 to $1.79 \mathrm{~m}^{2}$ group $(\overline{\mathrm{x}}=2.04 \pm 0.21)$ to the more than $1.8 \mathrm{~m}^{2}$ group $(\overline{\mathrm{x}}=2 \cdot 23 \pm 0.37)$. The difference between the 1.6 to $1.69 \mathrm{~m}^{2}$ group and the greater than $1.8 \mathrm{~m}^{2}$ group is significant $(\mathrm{p}<0.05)$.

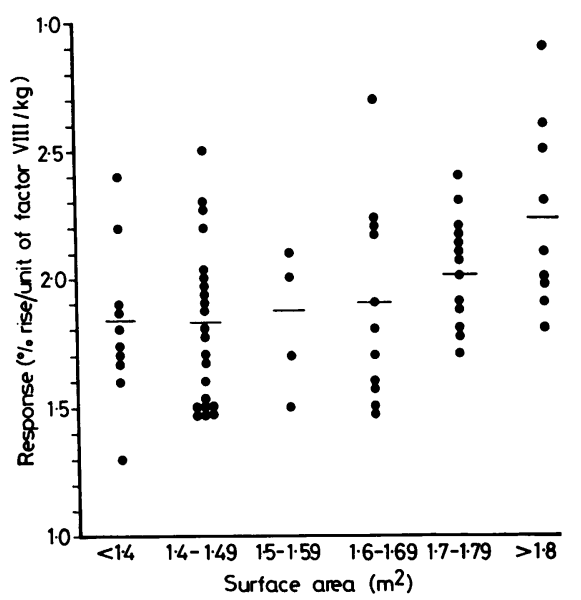

Fig. 2 Effect of increasing surface area on the dose response.

\section{EFFECT OF INCREASING DOSES OF FACTOR} VIII

The scattergram shows the relation of the in vivo response to varying doses of factor VIII (Fig. 3). There is no correlation between these two parameters $(\mathrm{r}=\mathbf{0} \cdot 38)$.

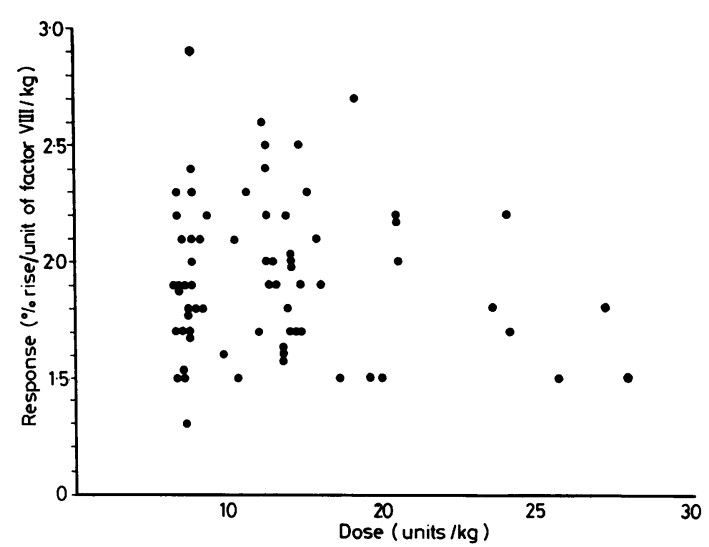

Fig. 3 Effect of increasing doses of factor VIII on the in vivo response.

INDIVIDUAL VARIATIONS

The variations between responses of the 14 boys who had their responses estimated on more than one occasion are shown in Fig. 4.

\section{EFFECT OF VARYING HAEMOGLOBIN}

CONCENTRATIONS

Haemoglobin concentrations were available on 37 occasions within one month of recovery estimations. Only one boy was found to be anaemic 


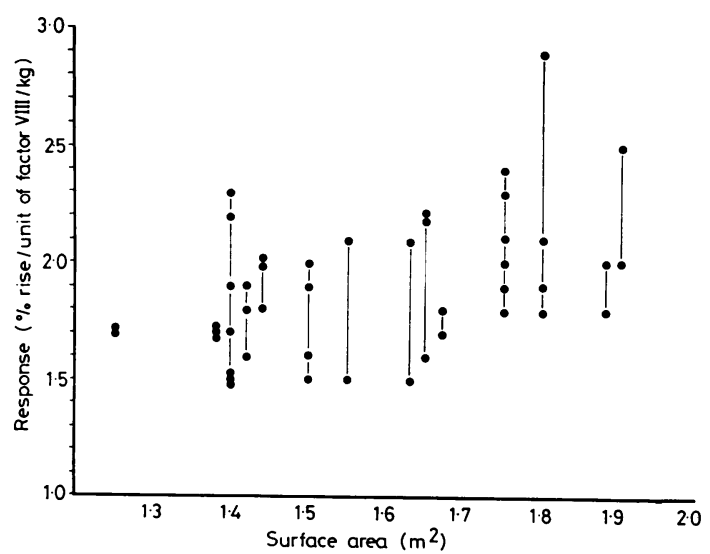

Fig. 4 Varying dose response in individuals tested on more than one occasion.

(Hb 8.0 g/dl). Recoveries were estimated on three occasions at this level, and found to be 1.5, 1.6 and $1 \cdot 9$. The remaining 33 haemoglobin concentrations ranged between 13.0 and $16.0 \mathrm{~g} / \mathrm{dl}$. No significant correlation was found between the haemoglobin concentrations and recovery $(s=+87, r=0 \cdot 13)$.

\section{Discussion}

The inconsistent individual variations in response rule out the possibility of predicting the recovery of factor VIII in an individual. Some of these variations may be due to inconsistencies in the factor VIII assay. It is apparent that variations in the dosage of factor VIII administered do not affect the in vivo response.

In vivo recovery of factor VIII appears to increase steadily from less than $40 \mathrm{~kg}$ to $49 \mathrm{~kg}$, drops back, and then rises again from 55 to $69 \mathrm{~kg}$. The increasing response of the larger boys is confirmed when surface area is plotted against recovery, but no early rise of recovery in the smaller boys is noted. It is apparent that a rise of $2 \% /$ unit of factor VIII/kg does not become the norm until a surface area of $1.7 \mathrm{~m}^{2}$ has been reached although there is a large overlap between responses at the varying weights. The safest assumption to make below a surface area of $1.7 \mathrm{~m}^{2}$ is an in vivo recovery of not more than $1.5 \% /$ unit of factor VIII $/ \mathrm{kg}$.

While there is some variation in the confirmation of the manufacturer's unit-value, this is usually not more than $10 \%$ and of random distribution. The consistent increase in recovery with increasing surface area suggesst that variable potency is not likely to have a significant effect on our results.

Only one boy was anaemic and while two of his recoveries were below average, one was well into the high normal range. Overall we can see no correlation between haemoglobin concentrations and recovery, but not enough anaemic patients were available to test the hypothesis that haemoglobin concentrations might influence recovery. With modern surveillance fewer patients are likely to be anaemic and surface area therefore appears to be the most reliable indication of recovery.

This work was supported by a grant from Travenol laboratories. We thank Mrs SA Norris for typing the manuscript.

\section{References}

${ }^{1}$ Rizza CR. The management of haemophilia. Practitioner 1970;204:763-72.

${ }^{2}$ Levine PH, McVerry BA, Attock B, Dormandy KM. Health of the intensively treated haemophiliac, with special reference to abnormal liver chemistries and splenomegaly. Blood $1977 ; 50,1: 1-9$.

${ }^{3}$ Aronstam A. Factor VIII supply and demand. Br Med J $1980 ; 280: 32-3$.

4 Aronstam A, Wassef M, Choudhury DP, Turk PM, McLellan DS. Double-blind controlled trial of three dosage regimens in treatment of haemarthroses in haemophilia A. Lancet 1980;i: 169-71.

${ }^{5}$ Aronstam A, Wassef M, Hamad Z, McLellan DS. The effect of bleeding patterns on the response of haemophilic haemarthroses to different doses of factor VIII. Clin Haematol 1981 : (in press).

- Biggs R, Rizza CR. The treatment of haemophilia A and $B$ and von Willebrand's disease. In: Biggs R, ed. Oxford: Blackwell Scientific Publications, 1978: 181-202.

${ }^{7}$ Hilgartner, MW. Current therapy. Progress in Paediatric Haematology and Oncology 1976;1:151-70.

${ }^{8} \mathrm{Kasper} \mathrm{CK}$. In: Boone D, ed. Comprehensive management of haemophilia. Philadelphia: Davis, 1976: 3-17.

${ }^{9}$ Biggs R, Matthews JM. In: Biggs R, MacFarlane RG, eds. Treatment of haemophilia and other coagulation disorders Oxford: Blackwells, 1966: 107-28.

${ }^{10}$ Lurie A. The laboratory assessment of the efficacy of antihaemophilic therapy. $S$ Afr Med J 1972;46:844.

11 Denson KWE. In: Biggs R, ed. Human blood coagulation, haemostasis and thrombosis. Oxford: Blackwell Scientific Publications, 1972: appendix 2, 616.

${ }^{12} \mathrm{Du}$ Bois D, Du Bois EF. Clinical colorimetry $\mathrm{X}$ formula to estimate the approximate surface area if height and weight be known. Arch Intern Med 1916;17:863-71.

Requests for reprints to: Dr A Aronstam, Treloar Haemophilia Laboratory, Lord Mayor Treloar Hospital, Alton, Hampshire, England. 